\title{
GENERALIZED MOSAIC NEUROFIBROMATOSIS TYPE 1 : A RARE CASE REPORT
}

\author{
Parajuli $N^{1^{*}}$, Bhaskar $M M K^{2}$, Shrestha $R^{3}$, Karki $A^{3}$, Lama $L^{3}$
}

\section{Affiliation}

1. Consultant Dematologist, Department of dermatology, National Academy of Medical Sciences, Bir Hospital, Nepal

2. Professor, Department of dermatology, National Academy of Medical Sciences, Bir Hospital, Nepal

3. Associate Professor, Department of dermatology, National Academy of Medical Sciences, Bir Hospital, Nepal

\section{ARTICLE INFO}

\section{Article History}

Received : 13 February, 2018

Accepted : 1 April, 2018

Published : 30 April, 2018

(C) Authors retain copyright and grant the journal right of first publication with the work simultaneously licensed under Creative Commons Attribution License CC - BY 4.0 that allows others to share the work with an acknowledgment of the work's authorship and initial publication in this journal.

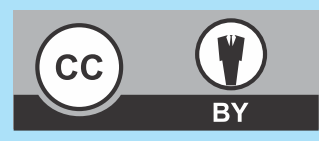

\section{CR 17}

DOI: $\underline{\text { http://dx.doi.org/10.3126/bjhs.v3i1.19769 }}$

\author{
* Corresponding Author \\ Dr. NirajParajuli \\ Consultant dermatologist \\ Department of dermatology and venereology \\ National Academy of Medical Sciences, \\ Bir Hospital, Kathmandu, Nepal \\ Email: drnirajparajuli@gmail.com \\ https://orcid.org/0000-0001-6869-4959
}

\section{Citation}

Parajuli N,Karki A, Laila L, Shrestha R,Bhaskar MMK. Generalized Mosaic Neurofibromatosis Type 1: A Rare Case Report. BJHS 2018;3(1)5:390-392

\section{ABSTRACT}

Neurofibromatosis (NF) consists of group of genetically inherited disorders all of which is characterized by occurrence of nerve sheath tumors. There are eight different subtypes of neurofibromatosis. Segmental NF, a rare mosaic pattern of NF- type1 (NF1) is diagnosed in individuals who have typical features of NF1 restricted to one part of the body and whose parents are both unaffected. But recently the nomenclature has been changed to mosaic NF.

We report a case of neurofibromatosis following the lines of blaschko. To the best of our knowledge, no such case report has been published till date of generalized mosaic NF following lines of blaschko's bilaterally symmetrically.

\section{KEYWORDS}

Blaschko, mosaic, neurofibromatosis, segmental 


\section{INTRODUCTION}

Neurofibromatosis(NF) consists of group of genetically inherited disorders all of which is characterized by occurrence of nerve sheath tumors. The mode of inheritance is autosomal dominant with a high rate of new mutation and variable expression. ${ }^{1}$ There are eight different subtypes of neurofibromatosis. ${ }^{2}$ The prevalence of neurofibromatosis type 1 (NF1) is about 1 in $3000 .{ }^{3}$ The diagnosis of NF 1 is based on presence of $\geq 2$ features out of the seven criteria. ${ }^{4}$ It is caused by heterozygous mutations of the NF1 gene located in chromosome 17q11.2.

Segmental neurofibromatosis is a rare mosaic pattern of NF1 which presents with typical features of NF1 restricted to one part of the body and whose parents are both unaffected. ${ }^{6,7}$ The presentation can be limited to a narrow strip of one quadrant to occasionally to whole half of the body. ${ }^{7}$

Here, we report a case of 52 years old male who presented with freckling, multiple lentigines, café-au-lait macules (CALM) and neurofibroma in a blaschkoid pattern bilaterally, which to our knowledge has not been reported till date.

\section{CASE REPORT}

A 52 years old male came to dermatology out-patient department with Tinea cruris. But, on further examination for signs of fungal infection elsewhere, multiplecafé-au-lait macules and freckles along with lentigines were noted.

On further questioning, patient mentioned a few grouped soft nodules over the right abdomen. Patient was not exactly sure but claimed that both the pigmentary changes and the nodules were present for more than 25 years.

There was no history of similar skin lesion in other family members. No history of any bony abnormalities or seizures. Patient was literate but was not able to complete high school because of family problems. He was an overseas foreign worker currently placed in middle east.

No major illness or surgeries were noted in the past.

On examination, there were multiple lentigines and freckles following a pattern extending from the forearm, involving the axilla bilaterally and converging in the mid-abdomen. (Figure 1a)Similarly grouped lentigines following a linear pattern was also noted in the back. (Figure 1b). Multiple freckles were also noted in the axilla bilaterally. (figure 2)

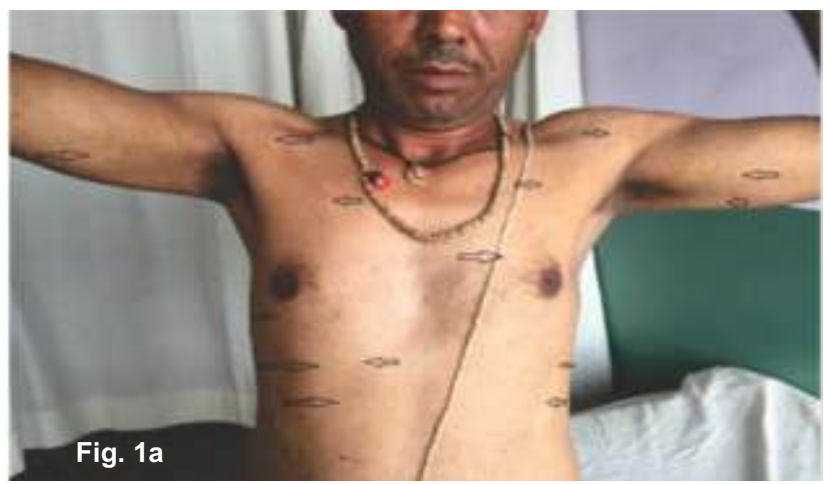

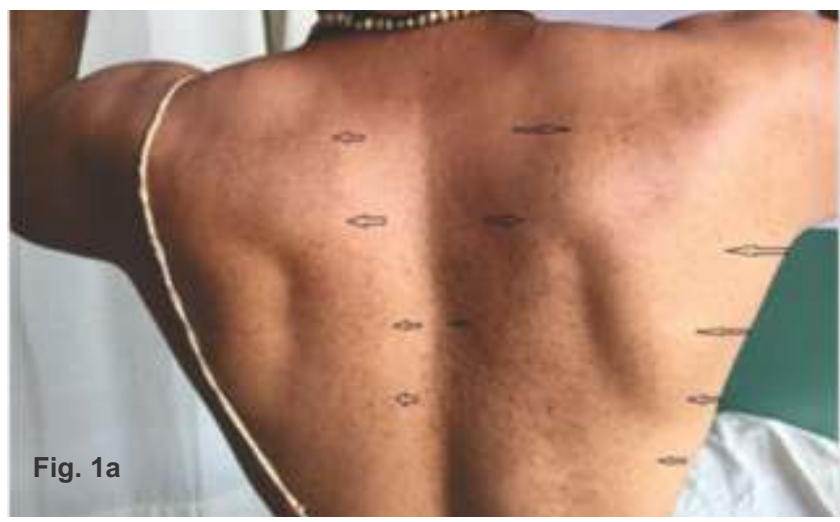

Figure 1a and 1b: Multiple lentiginesand freckles in the bhaschkoid pattern over the trunk)

There were multiple cafe-an-lait macules (CALMs), many of them greater than $1.5 \mathrm{~cm}$ each. (Figure 2)

Multiple soft skin colored nodules were noted on right side of chest and abdomen. (Figure 3) The nodules were soft in consistency, mobile and demonstrated "button- hole" sign.

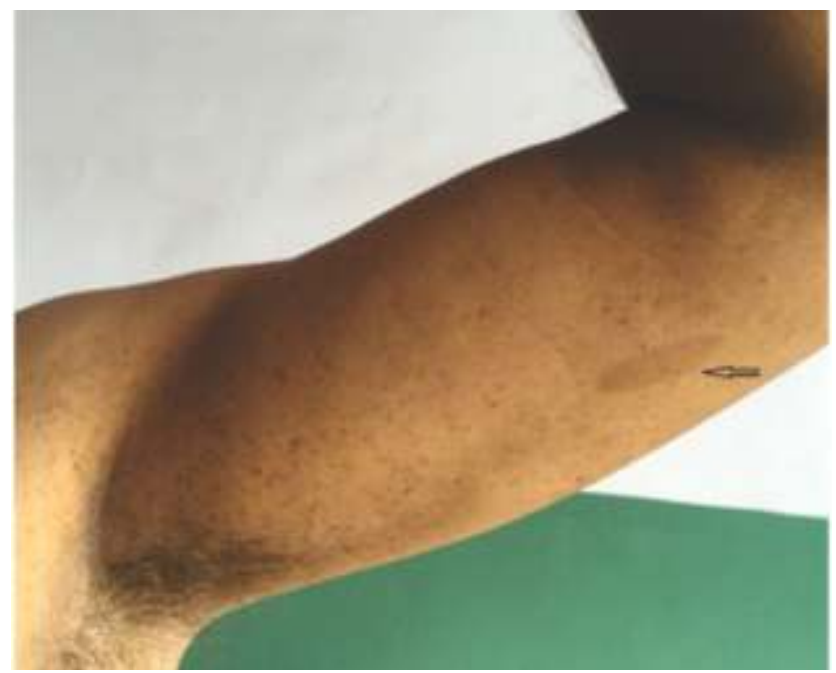

Figure 2: Axillary freckling (arrowhead) and café-au-lait macules (arrow)

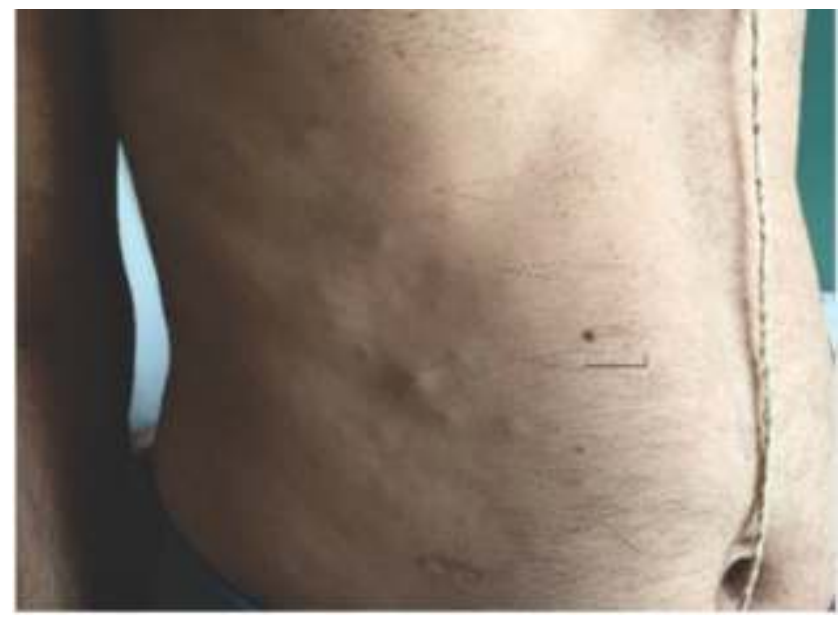

Figure 3: Multiple soft skin-colored nodules on right side of abdomen (arrow). On pressing with the index finger, the buttonhole sign was present.

(Note: the string is of religious significance) 
Ophthalmologic and neurologic examination did not reveal any abnormalities. Patient neither consented for any radiological examination nor biopsy of skin nodules.

The presence of axillary freckling and multiple CALMs made us label the case as NF 1, as per the diagnostic criteria. ${ }^{4}$ But from the presence of the freckles and CALMs along with the soft tumors in a blasckoid pattern, we made the diagnosis of generalized mosaic neurofibromatosis.

Patient was explained on the course and prognosis of the disease and was advised for regular follow-up.

\section{DISCUSSION}

Neurofibromatosis is classified into eight subtypes. Among these, NF type $V$ is classified as segmental ${ }^{2}$. Segmental NF is defined as presence of CALMs and neurofibromas to given area of the body with no crossing of midline, absence of any family history of NF and systemic symptoms. Segmental NF is further classified into subtypes which include true segmental, localized with deep involvement, hereditary and bilateral. ${ }^{8}$

Segmental NF is an example of mosaicism, in which localized disease results from a postzygotic NF1 gene mutation. ${ }^{9}$ Localized disease is manifested if mutation occurs late in embryogenesis, whereas mutation occurring before tissue differentiation causes generalized disease. ${ }^{7}$

But after recognition of the somatic mutation involved in these subtype, recent suggestion is to use correct term as "mosaic" NF rather than type V or segmental. ${ }^{10}$ In 2001, Ruggieri and Huson divided neurofibromatosis with somatic mutation into 2 distinct subsets mosaic localized and mosaic generalized based specifically on the time of mutation. $^{7}$
A systemic review of 320 individuals with segmental neurofibromatosis found out that most of patients (80\%) had unilateral findings and only $20 \%$ of patients had bilateral findings. But still there was no report on bilateral symmetrical blaschkoid pattern of distribution. ${ }^{10}$ Similarly, other case reports still did not mention on this unique pattern of distribution.

This case is unique in that the lesion seems to be following the lines of blaschko symmetrically. There is no family history of neurofibromatosis. The nodules showing buttonhole sign were very suggestive of neurofibroma.

To our best of knowledge, this is the first of the such case report which fits the subtype of generalized mosaic NF following the lines of blaschko bilaterally.

\section{LIMITATION OF THE STUDY}

A skin biopsy which is diagnostic of neurofibroma could not be done. An ultrasound of abdomen and pelvis as well as a chest $x$-ray could have shown any internal organ involvement which was also not done because patient did not agree for any investigation.

\section{CONCLUSION}

Mosaic generalized neurofibromatosis is a rare variant. It should be suspected in cases which presents with unusual presentation of neurofibromas. A better nomenclature of mosaic neurofibromatosis should be encouraged over the previously used segmental neurofibromatosis.

\section{CONFLICT OF INTEREST}

none

\section{REFERENCES}

1. Korf BR. Neurofibromatosis. Handb Clin Neurol. 2013;111: 333-40. doi: 10.1016/B978-0-444-52891-9.00039-7.

2. Riccardi VM. Neurofibromatosis: clinical heterogeneity. Curr Probl Cancer. 1982 Aug;7(2):1-34. PMID: 6816509

3. Friedman JM. Epidemiology of neurofibromatosis type 1. Am J Med Genet. 1999 Mar 26;89(1):1-6. PMID: 10469430

4. Neurofibromatosis. Conference statement. National Institutes of Health Consensus Development Conference. Arch Neurol. 1988 May;45(5):575-8. PMID: 3128965

6. Listernick R, Mancini AJ, Charrow J. Segmental neurofibromatosis in childhood. Am J Med Genet A. 2003 Aug 30;121A(2):132-5. doi: 10.1002/ajmg.a.20183

7. Ruggieri M, Huson SM. The clinical and diagnostic implications of mosaicism in the neurofibromatoses. Neurology. 2001 Jun 12;56(11):1433-43. PMID: 11409413

8. Roth RR, Martines R, James WD. Segmental neurofibromatosis. Arch Dermatol. 1987 Jul;123(7):917-20. PMID: 3111388

5. Jett K, Friedman JM. Clinical and genetic aspects of neurofi bromatosis 1. Genet Med. 2010 Jan;12(1):1-11. doi: 10.1097/ GIM.0b013e3181bf15e3. 